\title{
Images
}

\section{Get off the back burner!}

\author{
Chris Keefer, MD*; Julia Carrol, $\mathrm{MD}^{\dagger}$; David Carr, $\mathrm{MD}^{\ddagger}$
}

A 65-year-old male presented with chronic mechanical back pain and a 6-month history of a discrete, hyperpigmented reticular rash on his lower back. On further questioning, the patient admitted to daily use of an electric heating pad over the distribution of the rash (Figure 1).

The diagnosis was erythema ab igne (EAI). Historically, EAI has been associated with repeated and prolonged exposure to radiant heat sources used in cold climates, such as fireplaces and woodstoves, and its incidence has greatly decreased with the advent of central heating. ${ }^{1}$ Although few epidemiologic data are available regarding the modern-day incidence of EAI in North America, a number of modern case reports describe EAI with the use of hot water bottles, electric blankets, and laptop computers. ${ }^{2}$ With the rise in personal computer use, "laptop legs" has come to be a colloquial term for EAI of the anterior thighs. The pathogenesis of EAI involves repeated heat exposures insufficient to cause a burn but that result in transient increases in skin temperatures to 43 to $47^{\circ} \mathrm{C}\left(109.4-116.6^{\circ} \mathrm{F}\right)$. This repetitive heat stress can lead to reticulate hypermelanosis, superficial epidermal atrophy, and diffuse hyperkeratosis. ${ }^{1,3}$ The lesions of EAI can predispose an individual to the development of squamous cell carcinomas. ${ }^{4}$ The differential diagnosis for the lace-like hyperpigmented rash of EAI includes acanthosis nigricans, livedo reticularis, and poikiloderma atrophican vasculare.

If in doubt, referral to a dermatologist may lead to a definitive diagnosis of an underlying endocrine, autoimmune, or malignant disease. EAI may be seen in the emergency department due to the frequent presentation of mechanical back pain and physician encouragement of the use of heating pads for pain management..$^{5}$ Treatment consists primarily of discontinuation of the culprit heat source. Persistent hyperpigmentation has been successfully treated with 5-fluorouracil, tretinoin, and hydroquinone. ${ }^{1,6}$

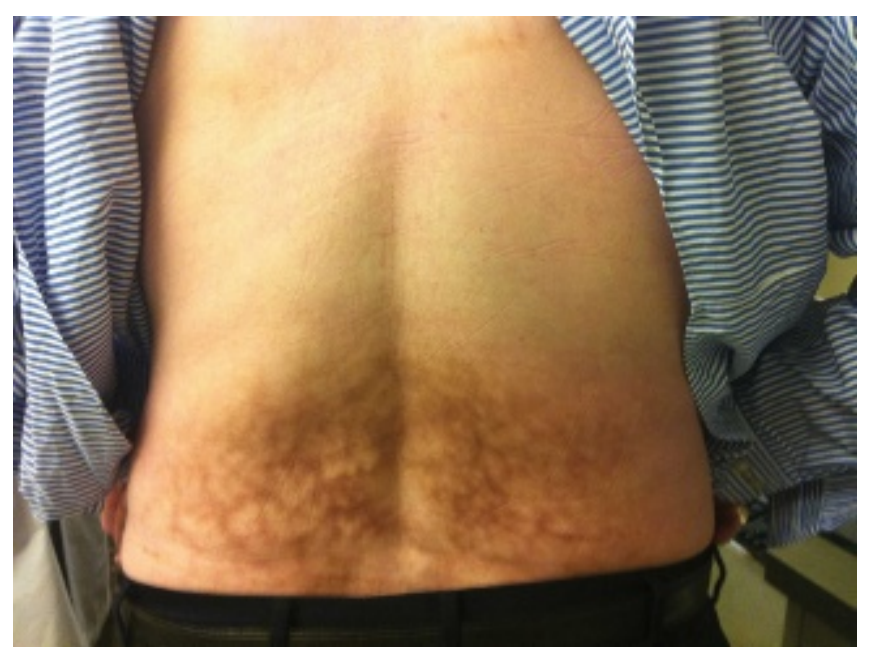

Figure 1. Erythema ab igne on the back.

Competing interests: None declared.

Keywords: back pain, chronic pain, thermal injury

\section{REFERENCES}

1. Tan S, Bertucci V. Erythema igne; an old condition new again. CMA7 2000;162:77-8.

2. Giraldi S, Abbage KT, Marinoni LP, et al. Erythema ab igne induced by a laptop computer in an adolescent. An Bras Dermatol 2011;86:128-30, doi:10.1590/S0365-05962011000100018.

3. Alotaibi L. Erythema ab igne. Available at: Emedicine. medscape.com/article/1087535-overview\#a0104 (accessed September 9, 2011).

4. Wharton JB, Sheehan DJ, Lesher JL. Squamous cell carcinoma in situ arising in the setting of erythema ab igne. 7 Drugs Dermatol 2008;7:488-9.

5. Chou R, Huffman LH. Nonpharmacologic therapies for acute and chronic low back pain: a review of the evidence for an American Pain Society/American College of Physicians clinical practice guideline. Ann Intern Med 2008;148:247-8.

6. Sahl WJ Jr, Taira JW. Erythema ab igne: treatment with 5fluorouracil cream. I Am Acad Dermatol 1992;27:109-10, doi:10.1016/S0190-9622(08)80818-3.

From the *Department of Family Medicine, McMaster University, Hamilton, ON; †Department of Dermatology, Medcan Clinic, Toronto, ON; $¥ D e p a r t m e n t$ of Emergency Medicine, University Health Network, Toronto, ON.

Correspondence to: Dr. Chris Keefer, William Osler Health Services, Brampton Civic Hospital, 2100 Bovaird Drive, East Brampton, ON L6R 3J7; chris.keefer@medportal.ca.

This article has been peer reviewed. 